\title{
Immunoregulation in the testis and its implication in fertility and infections
}

\author{
Kushaan Khambata ${ }^{1}\left(\mathbb{0}\right.$, Deepak N. Modi $^{2}$ (D) Satish K. Gupta ${ }^{*}$ (1) \\ ${ }^{1}$ Neuroendocrinology Department, National Institute for Research in Reproductive Health, J. M. Street, Parel, Mumbai \\ 400012, India \\ ${ }^{2}$ Molecular and Cellular Biology Lab, National Institute for Research in Reproductive Health, J. M. Street, Parel, Mumbai \\ 400012, India \\ ${ }^{3}$ Basic Medical Sciences Division, Indian Council for Medical Research, V. Ramalingaswami Bhawan, Ansari Nagar, New Delhi \\ 110029, India
}

*Correspondence: Satish K. Gupta, Basic Medical Sciences Division, Indian Council for Medical Research, V. Ramalingaswami Bhawan, Ansari Nagar, New Delhi 110029, India. skgupta.nii53@gmail.com

Academic Editor: Robert H. Miller, George Washington University School of Medicine \& Health Sciences, USA

Received: September 8, 2021 Accepted: November 3, 2021 Published: December 31, 2021

Cite this article: Khambata K, Modi DN, Gupta SK. Immunoregulation in the testis and its implication in fertility and infections. Explor Immunol. 2021;1:309-24. https://doi.org/10.37349/ei.2021.00021

\begin{abstract}
The testis is designated as one of the immune previleged sites in the body and harbours a unique immunoregulatory environment, which is important for preventing an immune response against sperm antigens which otherwise are recognized as "foreign" by the immune system. The blood-testis barrier along with the unique immune cells repertoire and various immunoregulatory \& immunosuppressive factors secreted by the Leydig cells, Sertoli cells and peritubular cells act in concert to maintain the tolerogenic environment in the testis. Abberations in immunotolerant mechanisms in the testis can lead to generation of anti-sperm antibodies that have an association with male infertility. It can also lead to inflammatory conditions of the male reproductive tract manifested as epididymitis and orchitis, generally due to bacterial or viral infections. In addition, non-infectious epididymitis and orchitis, having autoimmune origin have also been reported in males. While the immune privilege status of human testis protects the germ cells from an immune attack, it can also make the testis a succeptible reservoir for viruses such as human immunodeficiency virus-1, Zika virus and severe acute respiratory syndrome coronavirus-2, all of which have adverse consequences on male reproduction.
\end{abstract}

\section{Keywords}

Blood-testis barrier, immune cells, immune previlege, infertility, anti-sperm antibody, epididymitis, orchitis, infection, autoimmunity

\section{Introduction}

In humans, the male gonad, testis is primarily separated into two functional compartments: the seminiferous epithelium (spermatogenic compartment) and the surrounding interstitial tissue (endocrine compartment).

(C) The Author(s) 2021. This is an Open Access article licensed under a Creative Commons Attribution 4.0 International License (https://creativecommons.org/licenses/by/4.0/), which permits unrestricted use, sharing, adaptation, distribution and reproduction in any medium or format, for any purpose, even commercially, as long as you give appropriate credit to the original author(s) and the source, provide a link to the Creative Commons license, and indicate if changes were made. 
The seminiferous tubules are avascular and devoid of any blood vessels. In contrast, the interstitial tissue is highly vascularised with blood and lymphatic vessels. The interstitial tissue is chiefly populated by the Leydig cells, which perform the main endocrine function of androgen production. In seminiferous epithelium, diploid spermatogonia divide mitotically until some differentiate and enter meiosis to give rise to tetraploid primary spermatocytes. The haploid round spermatids then undergo differentiation to form elongated spermatids, which are finally released in the lumen of seminiferous tubules as highly specialized spermatozoa. The entire process of spermatogenesis is intricately regulated by several endocrine, autocrine and paracrine factors [1].

The process of spermatogenesis initiates at puberty, which is after the development of immune competence to recognise "self" antigens and establishment of the peripheral immune tolerance. Hence, the cellular proteins and other antigens on the meiotic and post-meiotic germ cells like the spermatozoa can be identified as "foreign" by the immune system. To circumvent this, the testis has a unique immunoregulatory environment, and is recognised as one of the immune privileged sites in the body [2,3]. This immune privilege environement in the testis protects the immunogenic germ cells from systemic immune attack. However, at the same time, the testis is enriched in the components of innate immunity to prevent microbial infections. Thus, maintenance of an appropriate balance between the immune modulatory mechanisms that protects the germ cells from autoimmune attack and yet protect the testis from infections is critical for successful spermatogenesis. Disruption of the testicular immune homeostasis can lead to autoimmune infertility; it can also cause infections in the testes leading to orchitis, both of which are etiological factors for male infertility. Thus, a complete understanding of the immunology of the testis is crucial for development of rational modalities for management of male infertility and even for the development of contraceptives. This review aims to briefly describe various immuno-modulatory mechanisms responsible for immune tolerance to sperm autoantigens. Attempts will be made to collate the recent advances and data on the immune disorders of male reproduction which affect male fertility and health. We will also explore recent emerging conditions where the immune privileged status of the testis is exploited during viral infections.

\section{Immune privilege in the testis}

In the testis, the auto-antigenic germ cells are protected from immune attack by its unique structural components as well as local and systemic tolerance mechanisms, which are briefly described below.

\section{Structural component of testis, blood-testis barrier}

The blood-testis barrier (BTB) is one of the tightest blood-tissue barricade in mammals. It is formed by the specialised tight occluding junctions of the Sertoli cells and is responsible for physically sequestering all the spermatogenic cells beyond the pre-meiotic leptotene or zygotene stage in the seminiferous epithelium. Sertoli cells makes various types of cell junctions such as tight junctions, gap junctions, basal ectoplasmic specialization, and desmosome-like junctions at the base of seminiferous tubules. The tight junctions between adjacent Sertoli cells involve Occludin and Claudin 11, which are linked to the actin cytoskeleton through cytoplasmic plaque proteins [4]. Cx43 is the dominant protein in gap junctions present in seminiferous tubules that allows the passage of only small molecules less than $1 \mathrm{kDa}$ [5]. Cadherin-catenin complexes leads to the formation of basal ectoplasmic specialization which also plays an important role in BTB [6]. The desmosome-like junctions exist between Sertoli cells and between Sertoli and germ cells. The expression of various desmosomal proteins such as desmoglein-2, plakophilin-2, plakoglobin and demoplakin has been shown in Sertoli cells. Desmosome-like junctions regulate cell adhesion and junction assembly by interacting with tight junctions, gap junctions, and basal ectoplasmic specialization [7]. Further, hemidesmosomes are also present in the basal membrane of the seminiferous tubules formed by myoid cells. Expression of various proteins leading to the formation of specialized occluding junctions playing a role in BTB are schematically shown in Figure 1. This makes the neoantigens on the meiotic and haploid germ cells inaccessible to the immune cells present in the interstitial tissue.

However, it is now amply clear that the BTB is just one of the contributing factors towards the immune privilege in the testis [2]. Recent studies have suggested that not all antigens on the developing germ cells may be sequestered from the immune system. In fact, a proportion of meiotic germ cells antigens 
egress from the seminiferous tubules into the interstitium and maintain regulatory $\mathrm{T}$ (Treg; CD4 $4^{+}$Foxp $3^{+}$) cells dependent systemic tolerance [8]. Further, certain sperm-specific proteins are selectively released by the Sertoli cells in the testicular interstitial fluid which can be accessed by the immune system [9]. These studies have challenged the conventional belief that all antigens on the developing germ cells are uniformly sequestered from the immune system and suggest operation of additional mechanisms to maintain systemic tolerance.

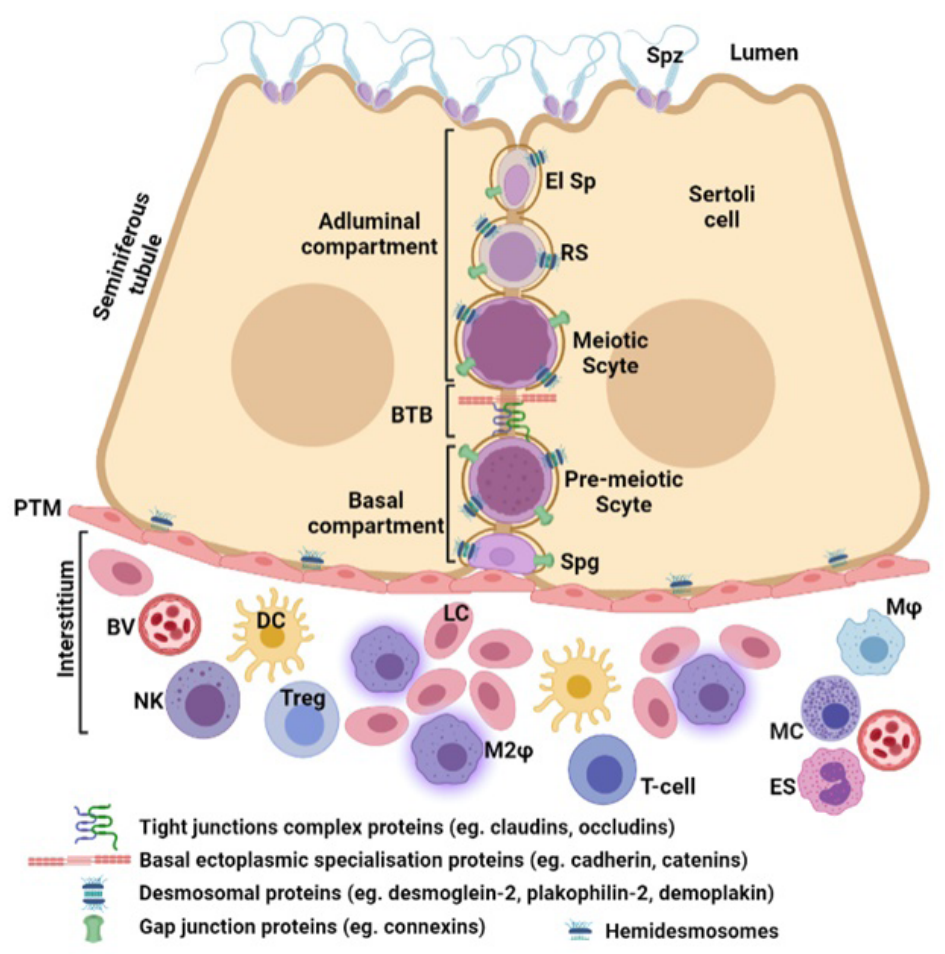

Figure 1. Mechnisms of immune privilege in the testis. Seminiferous tubules comprise of Sertoli cells in close association with germ cells. The BTB divides the seminiferous epitherlium into two compartments: basal compartment, containing the spermatogonia (Spg) and pre-meiotic spermatocytes (Scyte) and adluminal compartment containing metiotic and post meiotic germ cells like round (RS), elongating spermatids (EI Sp) and the mature spermatozoa (Spz). The BTB is mainly formed by tight junctions and basal ectoplasmic specialsations. Other cell junctions like desmosomes and gap junctions are also present between the germ cells and Sertoli cells. The peritubular myoid (PTM) cells form the basal membrane of seminiferous tubules. The interstitium contains blood vessels (BV) and is populated by Leydig cells (LC) along with immune cells like macrophages (M $\varphi$ ), alternately activated M2 macrophages (M2 $\varphi$ ), dendritic cells (DC), T- and Treg cells, natural killer (NK) cells, mast cells (MC), and eosinophils (ES)

Further, most of the developing spermatogenic cells do not express major histocompatibility complex (MHC) class I and II molecules [10]; although, the mature human sperm does express them [11]. Thus, the delayed expression of MHC molecules makes these cells less immunogenic and may play a role in the escape of recognition by the immune cells. Moreover, several testicular cells exhibit human leukocyte antigen-G (HLA-G) and HLA-E, which are implicated in suppression of the adaptive immune response [12].

\section{Immune cell repertoire in the testis}

Along with Leydig cells, several immune cells are present in the interstitial compartment [13], which are shown in Figure 1. Together these cells contribute towards maintaining the tolerogenic immune state in the testis (summarized in Table 1). Testicular macrophages represent the most abundant immune cells in the testis in most species, and exist in close physical and functional association with Leydig cells [14-16]. Majority of the macrophages in the testis are of the alternately activated M2 type (CD163) and produce interleukin-10 (IL-10) that have immunosuppressive and anti-inflammatory activities [17]. Beside the macrophages, dendritic cells are also found in the interstitium, although they are less in numbers under normal physiological conditions. Expression levels of MHC II antigens, co-stimulatory molecules such as CD80 and CD86 and chemokine receptor 7 (CCR7) suggest that the testicular dendritic cells are tolerogenic under normal physiological conditions [18]. The numbers of both macrophages and dendritic cells increase 
in infertile patients with chronic inflammation and their functions are also compromised [19]. In addition, suppressor T cells $\left(\mathrm{CD}^{+}\right)$, NK cells, and Treg cells are encountered in the interstitium [20,21]. Although they are sparsely distributed under normal circumstances, their numbers increase in infections and autoimmune conditions [13,22]. Granular leukocytes like mast cells are also present in the interstitium and are found to be increased in testicular inflammatory conditions [23]. However, the roles of NK cells and mast cells in maintaining testicular immune previlege is not clear.

Table 1. Induction of tolerance by the immune and other cells present in human testis

\begin{tabular}{ll}
\hline Cells & Special characteristics facilitating tolerance \\
\hline Macrophages & M2 alternatively activated, production of IL-10 \\
Dendritic cells & Low expression of MHC II, co-stimulatory molecules (CD80, CD86) and CCR7 \\
Suppressor T cells $\left(\mathrm{CD}^{+}\right)$ & Suppress immune response \\
Treg cells $\left(\mathrm{CD} 4^{+} / \mathrm{Foxp}^{+}\right)$ & Inhibit antigen-specific T cell responses \\
Sertoli cells & Production of immunosuppressive galectin-1, activin A and anti-inflammatory cytokines \\
Peritubular cells & Production of immunosuppressive activin A and expression of TLR \\
Leydig cells & Produce MIF and testosterone that have immunosuppressive properties \\
\hline
\end{tabular}

TLR: Toll-like receptors; MIF: migration inhibiting factor

\section{Immunoregulatory and immunosuppressive factors}

Sertoli cells, peritubular cells, and Leydig cells express and secrete several immunomodulatory molecules that are critical for maintaining the immune privilege environment in the testis (Table 1) [24, 25]. Sertoli cells produce galectin-1, which has an immunosuppressive property [26, 27]. In addition, Sertoli cells secretes anti-inflammatory cytokines and activin that help in suppressing the immune response [28]. Peritubular cells also help in making testicular environment immune tolerant by expressing activin A and TLR [29]. Under testicular inflammatory conditions, production of proinflammatory molecules such as tumor necrosis factor (TNF), IL-1, IL-6, monocyte chemotactic protein-1 and nitric oxide production is increased whereas IL-10 production is decreased [13, 30,31]. Leydig cells secrete macrophage MIF [32] that prevents cytotoxic activities of $\mathrm{T}$ cell and NK cells, thereby maintaining a tolerogenic environment. In addition, Leydig cells also secrete testosterone that is known to have immunosuppressive activity [33].

\section{Immunological disorders in men due to breach of immune tolerance in testis}

Disruptions in the testicular immune privilege could lead to autoimmunity and immune disorders, some of which are described below.

\section{Anti-sperm antibodies and their association with male infertility}

Formation of antibodies against the spermatozoa represent the most common and widely studied immune dysfunction of the male reproductive system. It is also listed as one of the factors causing infertility in men [34]. The presence of anti-sperm antibodies (ASA) can target the sperm for immune destruction, lead to a decrease in sperm motility, inhibit sperm penetration through the cervical mucus, and can affect sperm function by blocking receptors or molecules essential for fertilization thus leading to 'immune infertility' [35-38]. In contrast to other autoimmune disorders where immune response is generated against a specific dominant autoantigen, ASA are found to be directed towards multiple antigens, which may vary among individuals $[39,40]$.

There is a significant debate on the types of methods and source of samples to be used for detection of ASA. Although several studies had investigated the presence of ASA in seminal plasma and serum, it is now increasingly clear that only antibodies physically bound to the sperm are clinically significant $[36,41,42]$. Therefore, WHO has recommended detection of ASA on the surface of the ejaculated sperm by the direct antiglobulin-based tests such as the mixed anti-globulin reaction (MAR) test and the immunobead-binding test (IBT). These tests determine the percentage of motile sperm bound to the antibody, and a threshold of $50 \%$ of antibody-bound motile sperm are considered pathological $[38,43,44]$. Although ASA are found to be 
of immunoglobulin G (IgG) and IgA classes, it is suggested that presence of IgA-ASA is indicative of a mucosal immune response, which can impair sperm-cervical mucus interaction. Lastly, these tests are recommended to be used in conjunction with sperm function tests such as the post-coital test (PCT), which would determine the clinical consequence of ASA-bound sperm [36].

ASA are observed in 2-21\% of infertile men and several epidemiological studies have reported different incidence of ASA, mainly due to the differences in the study population, detection methods and thresholds chosen [34, 38, 45-47].There has been intense debate on the association of ASA with infertility as ASA bound sperm are also found among a small proportion of fertile men indicating that presence of ASA may not always lead to infertility $[45,48]$. This may be due to a variety of factors such as localisation of ASA to the spermatozoa (head, neck or tail region), functional relevance of the antigen(s) sequestered by ASA, immunoglobin classes involved and their proportion [37,38]. Several studies have associated ASA with reduced sperm counts and motility [47, 49]; however, inhibition of sperm penetration through the cervical mucus presents the main mechanism by which ASA interferes with fertility [37, 50]. Furthermore, ASA-positive infertile men had higher incidence of acrosome disorders, sperm DNA fragmentation, and increased reactive oxygen species (ROS) activity in washed spermatozoa samples of ASA group, all of which are detrimental to male fertility [46]. A recent large-scale retrospective study of infertile couples found that presence of 100\%-positive MAR test in normozospermic infertile men was significantly associated with negative PCT outcome, suggesting that a $100 \%$-positive MAR test can be a sole determinant of male infertility [34].

\section{Etiology of ASA}

Several studies have investigated the probable causes and risk factors for ASA production. However, only chronic obstructions to the male reproductive tract is proven to be a clear risk factor. Surgical procedures like vasectomy is widely accepted to be the most common cause of ASA formation. This is evident from the fact that most men (70\%) develop ASA after undergoing vasectomy due to the extravasation of sperm, and consistently report high ASA titres post-vasecctomy [51,52]. There is also an association between ASA and obstructive azoospermia and congenital absence of vas deferens [51, 52]. Although ASA are also reported in cases of testicular trauma, torsion, varicocele and other infectious and inflammatory conditions, there are several conflicting reports and lack of a concensus about a causal relationship [53]. Studies have also shown an increased incidence of other autoantibodies such as antinuclear antibodies and thyroglobulin antibodies in infertile men with ASA, suggesting that there may be an underlying genetic component towards ASA formation $[54,55]$.

\section{Treatment options to overcome male infertility due to ASA}

Previously, treatment of male infertility due to ASA used immunosuppressive drugs such as glucocorticoids. These drugs supressed the production of ASA, and led to limited success in improving prospects of pregnancy. However, treatment with glucocorticoids is frequently accompanied by side-effects, and hence are not recommended as the first line of treatment for ASA realted infertility [35, 56].

Assisted reproduction techniques (ART) are the current methods of choice in cases of male infertility attributed to sperm autoimmunity. However, success rates of ART like in vitro fertilisation (IVF) is negatively affected by the presence of ASA. Studies have shown that men with sperm-bound ASA experienced low fertilisation rates in IVF $[57,58]$, which could probably be due to ASA impeding the sperm-egg interactions. Intracytoplasmic sperm injection (ICSI), which involves direct injection of isolated spermatozoa into the oocyte cytoplasm, has been successfully used to overcome this problem. ICSI has yielded fertilisation and pregnancy rates comparable with ASA negative patients [59]. It has therefore become the best treatment modality in cases of male infertility due to sperm-bound ASA.

\section{Inflammatory conditions of male reproductive tract: epididymitis and orchitis}

Although male reproductive tract and testis in particular, have an immunologically modulated and constrained environment, it should be able to protect itself from external infections and pathogenic challenges. However, in instances where the immune mechanisms are overwhelmed (as in infection) or dysregulated (as in 
autoimmune response), inflammation ensues, which may have detrimental effecton male reproductive function and fertility. In fact, there is a high prevalence of asymptomatic testicular inflammatory lesions and immune complex formations in the basal membrane of seminiferous epithelium in infertile men [60,61]. Although it is difficult to ascertain whether they are due to autoimmune reactions or secondary to past infections as these may have occurred long before the patient presents for infertility. It is therefore essential to resolve inflammatory responses to limit long-term damage to the seminiferous epithelium.

Epididymitis is one of the most common intra-scrotal inflammatory conditions affecting 250-650 per 100,000 men each year [62]. It occurs more frequently than isolated orchitis, which is the inflammation of the testis. This could probably be due to closer proximity of epididymis to the external environment and differences in the immunoregulatory mechanisms of these two organs. However, many patients clinically presenting with epididymitis also have testicular inflammation (epididymo-orchitis), with epididymitis preceding the testicular involvement, especially when adequate treatment is delayed [63]. Despite the potential sequelae of male subfertility or infertility, there is no consistent epidemiological data for isolated orchitis and the incidence of epididymo-orchitis can only be calculated from the reports of epididymitis [61, 64]. The inflammatory conditions of epididymitis and epididymo-orchitis can be broadly divided into infectious and non-infectious autoimmune categories.

\section{Infectious epididymitis and orchitis}

\section{Etiological factors}

Among the infectious factors following pathogens are described as causative agents:

i) Bacterial infections: retrograde ascent of uropathogens like E. coli comprise the most common cause of acute epididymitis. Infections from sexually transmittable pathogens like Chlamydia trachomatis and Neisseria gonorrhoeae ascending from the urethra are more prevalent in younger men (age $<35$ years) [65]. These infections can cause epididymo-orchitis secondary to epididymitis. Less frequently, systemic infections with Mycobacterium tuberculosis, Mycobacterium leprae, Treponema pallidum, and Brucella spp can cause hematogenous dissemination of the pathogen and are reported to cause granulomatous orchitis and epididymitis in endemic regions [63].

ii) Viral infections: systemic infection with viruses like mumps is the most common cause of isolated orchitis in pubertal and post-pubertal males in areas with inadequate vaccination. In countries with good public health practices and vaccination, orchitis is rare in post-pubertal men [66]. Orchitis can also occur due to viral infections with Coxsackie virus type, Epstein-Barr, influenza and human immunodeficiency virus (HIV) [61]. The recent emerging infections affecting the testis will be reviewed in the subsequent sections.

\section{Clinical presentation and diagnosis}

Patients with epididymitis present with painful uni- or bilateral scrotal swelling, frequently accompanied by fever, lower urinary tract irritation, and discharge [63]. Scrotal palpation may reveal presence of a hydrocele. Microbiological urine analysis is often done to ascertain the causative pathogen, and scrotal ultrasound may be recommended in complicated cases of epididymo-orchitis. Most cases of isolated orchitis are associated with mumps, where orchitis presents as painful uni- or bi-lateral testis inflammation 3-10 days after onset of parotitis [64]. Histopathological investigations may reveal massive infiltration of interstitial compartment and seminiferous tubules with neutrophils in cases of bacterial epididymo-orchitis. Whereas, viral orchitis typically involves multifocal peri-vascular as well as peri- \& intra-tubular infiltration with macrophages, lymphocytes, neutrophils and plasma cell, which is often accompanied by degeneration of seminiferous epithelium [61]. Although there is scarce epidemiological data, bacterial epididymo-orchitis has been shown to cause hypo-spermatogenesis and detrimentally affect semen parameters [67].

\section{Treatment and therapy}

The 2016 European guideline on the management of epididymo-orchitis [68] and Centers for Disease Control and Prevention, USA (https://www.cdc.gov/std/treatment-guidelines/epididymitis.htm) have emphasised on early detection and management of epididymo-orchitis to improve patient outcomes and prevent long- 
term complications and sequalae. Ceftriaxone plus doxycycline is recommended for sexually-transmitted epididymo-orchitis and ofloxacin or levofloxacin have been endorsed to treat epididymo-orchitis due to enteric organisms $[65,68]$. Although, treatment with interferon- $\alpha 2 \mathrm{~B}$ (IFN- $\alpha 2 \mathrm{~B})$ during the acute phase of mumps infection has been suggested by some studies, it has not been found to be completely effective in preventing testicular atrophy $[64,69]$. In spite of the treatment with IFN- $\alpha 2 B$ during the acute phase of orchitis due to mumps infection, testicular biopsies revealed atrophy of seminiferous tubule [69].

\section{Non-infectious epididymitis and orchitis Etiology}

There is no reliable epidemiological data for the prevalence of autoimmune orchitis in general male population. The etiological factors contributing to non-infectious epididymitis and orchitis are poorly understood and still not well established; following factors are proposed:

i) Autoimmune orchitis may arise as a consequence of testicular seminoma that leads to extensive inflammation by immune activation due to neoplastic process [70]. In addition, physical injury during surgery like hernia repair or vasectomy, where the testicular antigens have been exposed to the immune system may also lead to orchitis [62].

ii) Autoimmune disorders like polyendocrinopathy syndrome 1 due to inactivating mutations of the autoimmune regulator gene, systemic lupus erythematosus and different forms of systemic vasculitis including Behçet's disease can also cause orchitis as one of the disease manifestations [71]. This suggests that an underlying genetic predisposition for development of autoimmunity can lead to autoimmune orchitis in presence of secondary triggers of infection or physical trauma.

iii) Granulomatous orchitis can sometimes also be idiopathic, where no specific cause be ascertained [72].

iv) Various drugs or chemical compounds may also lead to acute and chronic inflammatory conditions of the testis and/or epididymis [65].

\section{Clinical presentation, diagnosis and treatment}

Primary autoimmune orchitis is characterised by infertility with the formation of ASA directed towards the seminiferous epithelium [71]. These patients are commonly asymptomatic. Histopathology studies have demonstrated infiltration of lymphocytes in the interstitium and peritubular regions in a focal or multifocal manner in the testicular biopsies of asymptomatic infertile men in $50 \%$ of the cases. These infiltrates also correlated with the extent of damage to the germinal epithelium [61]. Immune cell infiltration composed of lymphocytes in the interstitial compartment of the testis has been reported in infertile men with non-obstructive azoospermia [61]. The degree of lymphocytic infiltration has been correlated with partial or complete loss of germinal epithelium, thickening of the lamina propria and complete tubular fibrosis. Autoimmune orchitis, which is secondary to the presence of other autoimmune conditions can be presented as painful scrotal oedema and imaging studies like ultrasound are used to confirm the diagnosis [71]. In contrast to infectious epididymitis/orchitis, there are no guidelines for treatment of autoimmune orchitis. ART techniques like ICSI are recommended for the treatment of infertility associated with primary autoimmune orchitis. Immunosuppressive medications can be used for the treatment of secondary autoimmune orchitis $[61,71]$.

\section{Flip side of immune privilege in the testis: increase susceptibility to viruses}

The immune privilege status of the testis has far wider implications than protecting the developing germ cells from the immune system. The mechanisms of immune privilege in the testis make it also a susceptible reservoir for viruses like HIV, Zika virus (ZIKV) and lately severe acute respiratory syndrome coronavirus-2 (SARS-CoV-2).

\section{HIV}

Acquired immunodeficiency syndrome (AIDS) caused by the HIV has emerged as one of major health issue of the last century affecting both developed and developing nations. Development of antiretroviral 
therapy has significantly extended the life expectancy of HIV infected individuals. One of the main challenges in cure of HIV is the emergence of viremia after completion of suppressive antiretroviral therapy. A leading factor contributing to this is the persistence of replication-competent HIV in cellular reservoirs like $\mathrm{CD}^{+}$memory $\mathrm{T}$ cells. Testis has been postulated to be one such site due to its suppressed immunoregulatory environment $[73,74]$.

There has been an intense debate on the status of testis as a viral compartment and sanctuary site during HIV infection [75]. It was initially thought that testis may contribute negligibly to the seminal viral load as there has been no difference in the seminal HIV-RNA after vasectomy [76]. However, resident testicular macrophages express the CD4, C-X-C motif chemokine receptor 4 (CXCR4), and CCR5 receptors for HIV-1 entry, which make them susceptible to infection, and can potentially constitute a reservoir for HIV $[77,78]$. There has been considerable controversy regarding the susceptibility of testicular germ cells to HIV infection [79-81]. It has been shown that though HIV is unable to infect germ cells, it binds to these cells using alternate receptors. The cell-associated infections through contact with infected testicular macrophage or lymphocyte are possible, leading to low level of viral replication and production [82]. Studies have shown that in HIV infected men (on suppressive antiretroviral therapy) with suppressed viral load ( $<50$ copies of HIV RNA/mL) in blood still harbour low levels of integrated HIV DNA in at least one testis [83]. It remains to be seen whether these can give rise to replication-competent viruses [84]. A recent study has further revealed that there is significant blood-testis genetic compartmentalisation of HIV DNA mainly due to differential clonal expansion of the infected immune cells in the blood and testis [85]. These findings may pose further complications for HIV eradication.

\section{ZIKV}

The ZIKV has been declared as a global public health emergency by the WHO after a major outbreak in 2016. The main mode of ZIKV transmission is through the bite of Ades mosquito in endemic regions. Although most ZIKV infections are asymptomatic, systemic infections can lead to development of common symptoms like fever, rashes, arthralgia, arthritis, myalgia, headache and Guillain-Barre syndrome in severe cases [86]. Besides the vector-borne transmission, sexual transmission has also emerged as an important route, with male-to-female transmission being more frequent [86]. These findings pose a grave concern as vertical transmission of the virus from infected mother to the developing fetus can cause various teratogenic effects such as the congenital Zika syndrome, which involves serious complications like microencephaly, cerebral abnormalities, intra uterine growth restriction and eye and hearing defects $[87,88]$.

Studies have shown that high loads of ZIKV RNA can persists in semen for longer durations (more than 6 months) than other body fluids like blood and urine [86, 89, 90]. Studies have reported persistent shedding of infectious ZIKV in semen for up to 30 days from the onset of symptoms, and presence of ZIKV RNA for much longer [90], suggesting that there is risk of sexual transmission even after symptoms are resolved. Moreover, sexual transmission has also been reported between asymptomatic individuals [91], and there are reports of detection of ZIKV in semen of vasectomised men [92]. These studies strongly suggest the tropism of ZIKV for the male genital tract even beyond the testis and epididymis. Studies have shown a transient decline in semen parameters like sperm count and motility along with disturbances in gonadotropin and steroid hormones in ZIKV infected men, suggesting a possible direct effect on spermatogenesis [93]. Mice models of ZIKV infection have demonstrated progressive testicular atrophy post-infection [94]; therefore, long-term effects on fertility in men cannot be ruled out and needs investigation.

ZIKV has been shown to infect a variety of testicular cells including the macrophages, peritubular cells, Leydig cells, Sertoli cells, and germ cells; and even produce replication competent viral particles [95]. It has been postulated that the ZIKV-infected macrophages can affect the tight junctions of the BTB and invade the seminiferous epithelium to disseminate the virus to the germ cells. Additionally, ZIKV can penetrate the adluminal compartment via the Sertoli cells, which are quite susceptible to ZIKV [96]. These findings implicate the testis as a potential long-term reservoir for ZIKV, even after peripheral clearance. Additionally, ZIKV can directly bind and infect the mature spermatozoa via the tyrosine kinase 3 receptors on the mid-piece $[93,97]$. 


\section{SARS-CoV-2}

The coronavirus disease-19 (COVID-19) pandemic caused by SARS-CoV-2 has spread worldwide and infected millions of men. Although controversies exist on the detection of SARS-CoV-2 RNA in semen [98], studies have detected viral shedding in seminal plasma during the active phase of infection [99]. However, unlike the ZIKV, SARS-CoV-2 does not persist in semen for longer periods and viral RNA is not detectable within 2 weeks of recovery [100]. The SARS-CoV-2 receptor angiotensin-converting enzyme 2 (ACE2) and the S protein cleavage enzyme TMPRSS2 are detected in testis [101]. Viral RNA and protein are also detected in the testis of men with COVID-19 implying that the coronaviruses can have an adverse impact on testicular health [102]. Indeed, degenerating germ cells have been reported in the testis of men with SARS-CoV-2. Sloughing of the spermatocytes was also noted along with swelling of the Sertoli cells and reduced number of Leydig cells [102-104].

SARS-CoV-2 infection systemically is associated with immune dysfunction in the testis. Significant interstitial edema and inflammatory infiltration with $\mathrm{T}$ cells are detected in testis of men infected with SARS-CoV-2 [103]. In addition, transcriptome profiling has revealed that inflammatory cytokines are upregulated in COVID-19 patient testes while genes asscoaited with spermatogenesis were reported to be downregulated. These data suggest that SARS-CoV-2 infection may lead to dysfunction of the genes that regulate spermatogenesis and inflammation-related pathways, thereby causing inflammatory immune attack in the testes and defects in spermatogenesis. Indeed, immunohistochemical staining demonstrated infiltration of $\mathrm{CD}^{+}{ }^{+}$lymphocytes, $\mathrm{CD} 20^{+} \mathrm{B}$ lymphocytes, $\mathrm{CD} 38^{+}$activated $\mathrm{B}$ cells, $\mathrm{CD} 68^{+}$macrophages $\mathrm{CD} 138^{+}$ plasma cells in the interstitial compartments of testis from patients with COVID-19, such infiltration were rarely detected in controls [102]. There is also IgG precipitation suggesting that SARS-CoV-2 might trigger a secondary autoimmune response and fuelling the primary pathogenesis of viral orchitis and consequent testicular damage [102].

\section{Concluding comments and future directions}

To conclude, it is evident that the immune system plays a central role in regulating male reproductive functions (Figure 2). There is an interplay of several immune mechanisms to prevent the developing male germ cells from eliciting an immune response. However, when these tolerogenic mechanisms are dysregulated, it can lead to activation of immune responses which may result in infertility or chronic inflammation. At the same time, the immune system has to protect the testis from external pathogenic agents and the immune privilege status of the testis is often exploited by viruses, which take refuge within the immunosuppressive microenvironment of the testis (Figure 2). While we gain further insights into the immunological mechanisms governing male reproductions, many unanswered questions remain.

\section{Immunoregulation in testis}

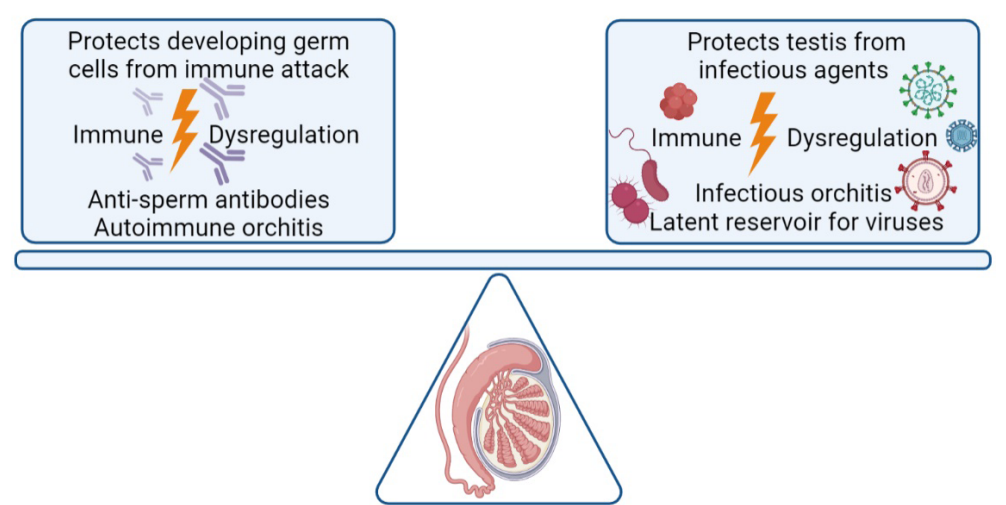

Figure 2. The balancing act of immune system in the testis. The immune system has to protect the developing germ cells from illiciting an immune response. When the tolerogenic mechanisms in the testis are dysregulated, it can lead to the formation of anti-sperm antibodies and autoimmune orchitis. On the other hand, the immune system must protect the testis from external pathogenic threats. When these mechansims fail, it can lead to infectious orchitis, and the testis can become a latent reservoir for viruses like HIV, ZIKV and SARS-CoV-2 
i) The higher incidence of ROS reported in ASA-positive sperm suggests that sperm oxidative stress could be one of the pathological factors causing sub-fertility [46]. It remains to be investigated whether this could lead to genetic or epigenetic defects in the ASA-positive sperm. This is especially important as ICSI is commonly used to resolve infertility resulting from ASA.

ii) Chronic pelvic pain is normally associated with epididymo-orchitis, which can be due to infection or physical injury. However, dysregulation of immune mechanisms can cause the inflammation to persist long after the clearance of infection or trauma is repaired. These conditions are still poorly understood and difficult to treat [105]. Thus, there is an obvious need for deeper insights into testicular and epididymal immunopathologies.

iii) While the viruses like HIV, ZIKV, and SARS-CoV-2 can 'hide-in' within the immune privileged environment of the testis, it has become critical to develop strategies to target removal of the virus. This would be especially challenging without the immune cells attacking the spermatogenic cells. Development of effective pharmacological interventions which can cross the BTB would play a key role. Alternatively, there is need to develop novel vaccination strategies that can generate humoral response to clear these viruses beore they take refuge in the testis.

We still have a long way to go to understand the complex interactions of the immune system and male reproductive system. Unravelling these mechanisms would be crucial to the clinical management of immune disorders which affect male fertility and health.

\section{Abbreviations}

ART: assisted reproduction techniques

ASA: anti-sperm antibodies

BTB: blood-testis barrier

CCR7: chemokine receptor 7

COVID-19: coronavirus disease-19

HIV: human immunodeficiency virus

ICSI: intracytoplasmic sperm injection

IgG: immunoglobulin G

IL-10: interleukin-10

MAR: mixed anti-globulin reaction

MHC: major histocompatibility complex

NK: natural killer

SARS-CoV-2: severe acute respiratory syndrome coronavirus-2

Treg: regulatory $\mathrm{T}$

ZIKV: Zika virus

\section{Declarations}

\section{Author contributions}

KK wrote the first draft of the manuscript. DM wrote the section on SARS-CoV-2. DM and SKG made critical changes, edited, and revised the manuscript. All authors approve the final version of the manscript.

\section{Conflicts of interest}

The authors declare that they have no conflicts of interest.

Ethical approval

Not applicable. 


\section{Consent to participate}

Not applicable.

Consent to publication

Not applicable.

Availability of data and materials

Not applicable.

Funding

KK and DM acknowledge Indian Council of Medical Research and Science and Engineering Research Board, Government of India, for funding. SKG acknowledge Indian Council of Medical Research, Government of India for the award of Emeritus Scientist. The funders had no role in study design, data collection and analysis, decision to publish, or preparation of the manuscript.

\section{Copyright}

(C) The Author(s) 2021.

\section{References}

1. Hess RA, de Franca LR. Spermatogenesis and cycle of the seminiferous epithelium. Adv Exp Med Biol. 2008;636:1-15.

2. Fijak M, Meinhardt A. The testis in immune privilege. Immunol Rev. 2006;213:66-81.

3. Qu N, Ogawa Y, Kuramasu M, Nagahori K, Sakabe K, Itoh M. Immunological microenvironment in the testis. Reprod Med Biol. 2020;19:24-31.

4. McCabe M, Foo C, Dinger M, Smooker P, Stanton P. Claudin-11 and occludin are major contributors to Sertoli cell tight junction function, in vitro. Asian J Androl. 2016;18:620-6.

5. Kidder GM, Cyr DG. Roles of connexins in testis development and spermatogenesis. Semin Cell Dev Biol. 2016;50:22-30.

6. Mruk DD, Cheng CY. The mammalian blood-testis barrier: its biology and regulation. Endocr Rev. 2015;36:564-91.

7. Lie PPY, Cheng CY, Mruk DD. The biology of the desmosome-like junction a versatile anchoring junction and signal transducer in the seminiferous epithelium. Int Rev Cell Mol Biol. 2011;223-69.

8. Tung KSK, Harakal J, Qiao H, Rival C, Li JCH, Paul AGA, et al. Egress of sperm autoantigen from seminiferous tubules maintains systemic tolerance. J Clin Invest. 2017;127:1046-60.

9. O’Donnell L, Rebourcet D, Dagley LF, Sgaier R, Infusini G, O'Shaughnessy PJ, et al. Sperm proteins and cancer-testis antigens are released by the seminiferous tubules in mice and men. FASEB J. 2021;35:e21397.

10. Pollanen P, Niemi M. Immunohistochemical identification of macrophages, lymphoid cells and HLA-antigens in the human testis. Int J Androl. 1987;10:37-42.

11. Martin-Villa JM, Longás J, Arnáiz-Villena A. Cyclic expression of HLA class I and II molecules on the surface of purified human spermatozoa and their control by serum inhibin B levels. Biol Reprod. 1999;61:1381-6.

12. Fiszer D, Ulbrecht M, Fernandez N, Johnson JP, Weiss EH, Kurpisz M. Analysis of HLA class Ib gene expression in male gametogenic cells. Eur J Immunol. 1997;27:1691-5.

13. Bhushan S, Theas MS, Guazzone VA, Jacobo P, Wang M, Fijak M, et al. Immune cell subtypes and their function in the testis. Front Immunol. 2020;11:583304.

14. Niemi M, Sharpe RM, Brown WRA. Macrophages in the interstitial tissue of the rat testis. Cell Tissue Res. 1986;243:337-44. 
15. Hoek A, Allaerts W, Leenen P, Schoemaker J, Drexhage HA. Dendritic cells and macrophages in the pituitary and the gonads. Evidence for their role in the fine regulation of the reproductive endocrine response. Eur J Endocrinol. 1997;136:8-24.

16. Meinhardt A, Bacher M, Metz C, Bucala R, Wreford N, Lan $\mathrm{H}$, et al. Local regulation of macrophage subsets in the adult rat testis: examination of the roles of the seminiferous tubules, testosterone, and macrophage-migration inhibitory factor. Biol Reprod. 1998;59:371-8.

17. Wang M, Fijak M, Hossain H, Markmann M, Nüsing RM, Lochnit G, et al. Characterization of the micro-environment of the testis that shapes the phenotype and function of testicular macrophages. J Immunol. 2017;198:4327-40.

18. Rival C, Lustig L, Iosub R, Guazzone VA, Schneider E, Meinhardt A, et al. Identification of a dendritic cell population in normal testis and in chronically inflamed testis of rats with autoimmune orchitis. Cell Tissue Res. 2006;324:311-8.

19. Duan YG, Yu CF, Novak N, Bieber T, Zhu CH, Schuppe HC, et al. Immunodeviation towards a Th17 immune response associated with testicular damage in azoospermic men. Int J Androl. 2011;34:e536-45.

20. Tompkins AB, Hutchinson P, de Kretser DM, Hedger MP. Characterization of lymphocytes in the adult rat testis by flow cytometry: effects of activin and transforming growth factor $\beta$ on lymphocyte subsets in vitro. Biol Reprod. 1998;58:943-51.

21. Jacobo P, Guazzone VA, Pérez CV, Lustig L. CD4 ${ }^{+}$Foxp3 ${ }^{+}$regulatory T cells in autoimmune orchitis: phenotypic and functional characterization. Am J Reprod Immunol. 2015;73:109-25.

22. el-Demiry MI, Hargreave TB, Busuttil A, Elton R, James K, Chisholm GD. Immunocompetent cells in human testis in health and disease. Fertil Steril. 1987;48:470-9.

23. Mayerhofer A, Walenta L, Mayer C, Eubler K, Welter H. Human testicular peritubular cells, mast cells and testicular inflammation. Andrologia. 2018;50:e13055.

24. Hedger MP, Qin JX, Robertson DM, de Kretser DM. Intragonadal regulation of immune system functions. Reprod Fertil Dev. 1990;2:263-80.

25. Doyle TJ, Kaur G, Putrevu SM, Dyson EL, Dyson M, McCunniff WT, et al. Immunoprotective properties of primary sertoli cells in mice: potential functional pathways that confer immune privilege. Biol Reprod. 2012;86:1-14.

26. Kaur G, Thompson LA, Dufour JM. Sertoli cells-immunological sentinels of spermatogenesis. Semin Cell Dev Biol. 2014;30:36-44.

27. Gao J, Wang X, Wang Y, Han F, Cai W, Zhao B, et al. Murine Sertoli cells promote the development of tolerogenic dendritic cells: a pivotal role of galectin-1. Immunology. 2016;148:253-65.

28. Hedger MP, Winnall WR. Regulation of activin and inhibin in the adult testis and the evidence for functional roles in spermatogenesis and immunoregulation. Mol Cell Endocrinol. 2012;359:30-42.

29. Mayer C, Adam M, Glashauser L, Dietrich K, Schwarzer JU, Köhn FM, et al. Sterile inflammation as a factor in human male infertility: involvement of Toll like receptor 2, biglycan and peritubular cells. Sci Rep. 2016;6:37128.

30. O’Bryan MK, Schlatt S, Gerdprasert O, Phillips DJ, de Kretser DM, Hedger MP. Inducible nitric oxide synthase in the rat tesis: evidence for potential roles in both normal function and inflammation-mediated infertility. Biol Reprod. 2000;63:1285-93.

31. Winnall WR, Muir JA, Hedger MP. Rat resident testicular macrophages have an alternatively activated phenotype and constitutively produce interleukin-10 in vitro. J Leuko Biol. 2011;90:133-43.

32. Meinhardt A, Bacher M, McFarlane JR, Metz CN, Seitz J, Hedger MP, et al. Macrophage migration inhibitory factor production by Leydig cells: evidence for a role in the regulation of testicular function. Endocrinology. 1996;137:5090-5. 
33. Fijak M, Schneider E, Klug J, Bhushan S, Hackstein H, Schuler G, et al. Testosterone replacement effectively inhibits the development of experimental autoimmune orchitis in rats: evidence for a direct role of testosterone on regulatory T cell expansion. J Immunol. 2011;186:5162-72.

34. Barbonetti A, Castellini C, D’Andrea S, Cordeschi G, Santucci R, Francavilla S, et al. Prevalence of anti-sperm antibodies and relationship of degree of sperm auto-immunization to semen parameters and post-coital test outcome: a retrospective analysis of over 10000 men. Hum Reprod. 2019;34:834-41.

35. Hendry WF. Detection and treatment of antispermatozoal antibodies in men. Reprod Fertil Dev. 1989;1:205-22.

36. Kremer J, Jager S. The significance of antisperm antibodies for sperm-cervical mucus interaction. Hum Reprod. 1992;7:781-4.

37. Chamley LW, Clarke GN. Antisperm antibodies and conception. Semin Immunopathol. 2007;29:169-84.

38. Vazquez-Levin MH, Marín-Briggiler CI, Veaute C. Antisperm antibodies: invaluable tools toward the identification of sperm proteins involved in fertilization. Am J Reprod Immunol. 2014;72:206-18.

39. Shetty J, Naaby-Hansen S, Shibahara H, Bronson R, Flickinger CJ, Herr JC. Human sperm proteome: immunodominant sperm surface antigens identified with sera from infertile men and women. Biol Reprod. 1999;61:61-9.

40. Bohring C, Krause E, Habermann B, Krause W. Isolation and identification of sperm membrane antigens recognized by antisperm antibodies, and their possible role in immunological infertility disease. Mol Hum Reprod. 2001;7:113-8.

41. Eggert-kruse W, Hofsäb $\beta$ A, Haury E, Tilgen W, Gerhard I, Runnebaum B. Relationship between local anti-sperm antibodies and sperm-mucus interaction in vitro and in vivo. Hum Reprod. 1991;6:267-76.

42. Barratt CL, Dunphy BC, Mcleod I, Cooke ID. The poor prognostic value of low to moderate levels of sperm surface-bound antibodies. Hum Reprod. 1992;7:95-8.

43. Lenzi A, Gandini L, Lombardo F, Rago R, Paoli D, Dondero F. Antisperm antibody detection: 2. clinical, biological, and statistical correlation between methods. Am J Reprod Immunol. 1997;38:224-30.

44. Sexual and Reproduction Health and Research. c 2021 WHO. WHO laboratory manual for the examination and processing of human semen (5th edition). 2010.

45. Sinisi AA, Finizio BD, Pasquali D, Scurini C, D’Apuzzo A, Bellastella A. Prevalence of antisperm antibodies by SpermMARtest in subjects undergoing a routine sperm analysis for infertility. Int $\mathrm{J}$ Androl. 1993;16:311-4.

46. Bozhedomov VA, Nikolaeva MA, Ushakova IV, Lipatova NA, Bozhedomova GE, Sukhikh GT. Functional deficit of sperm and fertility impairment in men with antisperm antibodies. J Reprod Immunol. 2015;112:95-101.

47. Verón GL, Molina RI, Tissera AD, Estofan GM, Marín-Briggiler CI, Vazquez-Levin MH. Incidence of sperm surface autoantibodies and relationship with routine semen parameters and sperm kinematics. Am J Reprod Immunol. 2016;76:59-69.

48. Heidenreich A, Bonfig R, Wilbert DM, Strohmaier WL, Engelmann UH. Risk factors for antisperm antibodies in infertile men. Am J Reprod Immunol. 1994;31:69-76.

49. Cui D, Han G, Shang Y, Liu C, Xia L, Li L, et al. Antisperm antibodies in infertile men and their effect on semen parameters: a systematic review and meta-analysis. Clin Chim Acta. 2015;444:29-36.

50. Bronson RA. Antisperm antibodies: a critical evaluation and clinical guidelines. J Reprod Immunol. 1999;45:159-83.

51. Sotolongo JR. Immunological effects of vasectomy. J Urol. 1982;127:1063-6.

52. Mazumdar S, Levine AS. Antisperm antibodies: etiology, pathogenesis, diagnosis, and treatment. Ferti Steril. 1998;70:799-810. 
53. Marconi $\mathrm{M}$ and Weidner $\mathrm{W}$. Site and risk factors of antisperm antibodies production in the male population. In: Krause W, Naz R, editors. Immune infertility. Springer; 2016. pp. 133-47.

54. Baker HW, Clarke GN, McGowan MP, Koh SH, Cauchi MN. Increased frequency of autoantibodies in men with sperm antibodies. Fertil Steril. 1985;43:438-41.

55. Paschke R, Bertelsbeck DS, Tsalimalma K, Nieschlag E. Association of sperm antibodies with other autoantibodies in infertile men. Am J Reprod Immunol. 1994;32:88-94.

56. McLachlan RI. Basis, diagnosis and treatment of immunological infertility in men. J Reprod Immunol. 2002;57:35-45.

57. Witkin SS, Viti D, David SS, Stangel J, Rosenwaks Z. Relation between antisperm antibodies and the rate of fertilization of human oocytes in vitro. J Assist Reprod Genet. 1992;9:9-13.

58. Ford WC, Williams KM, McLaughlin EA, Harrison S, Ray B, Hull MGR. The indirect immunobead test for seminal antisperm antibodies and fertilization rates at in-vitro fertilization. Hum Reprod. 1996;11:1418-22.

59. El-Sherbiny AF, Ali TA, Hassan EA, Mehaney AB, Elshemy HA. The prognostic value of seminal anti-sperm antibodies screening in men prepared for ICSI: a call to change the current antibody-directed viewpoint of sperm autoimmunity testing. Ther Adv Urol. 2021;13:1756287220981488.

60. Lehmann D, Emmons LR. Immunological phenomena observed in the testis and their possible role in infertility. Am J Reprod Immunol. 1989;19:43-52.

61. Schuppe HC, Meinhardt A, Allam JP, Bergmann M, Weidner W, Haidl G. Chronic orchitis: a neglected cause of male infertility? Andrologia. 2008;40:84-91.

62. Fijak M, Pilatz A, Hedger MP, Nicolas N, Bhushan S, Michel V, et al. Infectious, inflammatory and "autoimmune" male factor infertility: how do rodent models inform clinical practice? Hum Reprod Update. 2018;24:416-41.

63. Krieger JN. Epididymitis, orchitis, and related conditions. Sex Transm Dis. 1984;11:173-81.

64. Ludwig M. Diagnosis and therapy of acute prostatitis, epididymitis and orchitis. Andrologia. 2008;40:76-80.

65. Pilatz A, Hossain H, Kaiser R, Mankertz A, Schüttler CG, Domann E, et al. Acute epididymitis revisited: impact of molecular diagnostics on etiology and contemporary guideline recommendations. Eur Urol. 2015;68:428-35.

66. Willocks LJ, Guerendiain D, Austin HI, Morrison KE, Cameron RL, Templeton KE, et al. An outbreak of mumps with genetic strain variation in a highly vaccinated student population in Scotland. Epidemiol Infect. 2017;145:3219-25.

67. Osegbe DN. Testicular function affter unilateral bacterial epididymo-orchitis. Eur Urol. 1991;19:204-8.

68. Street EJ, Justice ED, Kopa Z, Portman MD, Ross JD, Skerlev M, et al. The 2016 European guideline on the management of epididymo-orchitis. Int J STD AIDS. 2017;28:744-9.

69. Yeniyol CO, Sorguc S, Minareci S, Ayder AR. Role of interferon-alpha-2B in prevention of testicular atrophy with unilateral mumps orchitis. Urology. 2000;55:931-3.

70. Klein B, Haggeney T, Fietz D, Indumathy S, Loveland KL, Hedger M, et al. Specific immune cell and cytokine characteristics of human testicular germ cell neoplasia. Hum Reprod. 2016;31:2192-202.

71. Silva CA, Cocuzza M, Carvalho JF, Bonfá E. Diagnosis and classification of autoimmune orchitis. Autoimmun Rev. 2014;13:431-4.

72. Roy S, Hooda S, Parwani AV. Idiopathic granulomatous orchitis. Pathol Res Pract. 2011;207:275-8.

73. Houzet L, Matusali G, Dejucq-Rainsford N. Origins of HIV-infected leukocytes and virions in semen. J Infect Dis. 2014;210 Suppl 3:622-30.

74. Stein J, Bonsmann MSG, Streeck H. Barriers to HIV cure. HLA. 2016;88:155-63. 
75. Lowe SH, Sankatsing SUC, Repping S, van der Veen F, Reiss P, Lange JMA, et al. Is the male genital tract really a sanctuary site for HIV? Arguments that it is not. AIDS. 2004;18:1353-62.

76. Krieger JN, Nirapathpongporn A, Chaiyaporn M, Peterson G, Nikolaeva I, Akridge R, et al. Vasectomy and human immunodeficiency virus type 1 in semen. J Urol. 1998;159:820-6.

77. Habasque C, Aubry F, Jégou B, Samson M. Study of the HIV-1 receptors CD4, CXCR4, CCR5 and CCR3 in the human and rat testis. Mol Hum Reprod. 2002;8:419-25.

78. Roulet V, Satie AP, Ruffault A, le Tortorec A, Denis H, Guist'hau O, et al. Susceptibility of human testis to human immunodeficiency virus-1 infection in situ and in vitro. Am J Pathol. 2006;169:2094-103.

79. Pudney J, Nguyen H, Xu C, Anderson DJ. Microscopic evidence against HIV-1 infection of germ cells or attachment to sperm. J Reprod Immunol. 1999;41:105-25.

80. Le Tortorec A, Dejucq-Rainsford N. HIV infection of the male genital tract-consequences for sexual transmission and reproduction. Int J Androl. 2010;33:e98-108.

81. Dejucq-Rainsford N, Jégou B. Viruses in semen and male genital tissues-consequences for the reproductive system and therapeutic perspectives. Curr Pharm Des. 2005;10:557-75.

82. Mahé D, Matusali G, Deleage C, Alvarenga RLLS, Satie AP, Pagliuzza A, et al. Potential for virus endogenization in humans through testicular germ cell infection: the case of HIV. J Virol. 2020;94:e01145-20.

83. Jenabian MA, Costiniuk CT, Mehraj V, Ghazawi FM, Fromentin R, Brousseau J, et al. Immune tolerance properties of the testicular tissue as a viral sanctuary site in ART-treated HIV-infected adults. AIDS. 2016;30:2777-86.

84. Darcis G, Coombs RW, Van Lint C. Exploring the anatomical HIV reservoirs: role of the testicular tissue. AIDS. 2016;30:2891-3.

85. Miller RL, Ponte R, Jones BR, Kinloch NN, Omondi FH, Jenabian MA, et al. HIV diversity and genetic compartmentalization in blood and testes during suppressive antiretroviral therapy. J Virol. 2019;93:e00755-19.

86. Kurscheidt FA, Mesquita CSS, Damke GMZF, Damke E, Carvalho ARBA, Suehiro TT, et al. Persistence and clinical relevance of Zika virus in the male genital tract. Nat Rev Urol. 2019;16:211-30.

87. Hamer DH, Wilson ME, Jean J, Chen LH. Epidemiology, prevention, and potential future treatments of sexually transmitted Zika virus infection. Curre Infect Dis Rep. 2017;19:16.

88. Pomar L, Musso D, Malinger G, Vouga M, Panchaud A, Baud D. Zika virus during pregnancy: from maternal exposure to congenital Zika virus syndrome. Prenat Diagn. 2019;39:420-30.

89. Paz-Bailey G, Rosenberg ES, Doyle K, Munoz-Jordan J, Santiago GA, Klein L, et al. Persistence of Zika virus in body fluids. N Engl J Med. 2017;379:1234-43.

90. Mead PS, Duggal NK, Hook SA, Delorey M, Fischer M, Olzenak McGuire D, et al. Zika virus shedding in semen of symptomatic infected men. N Engl J Med. 2018;378:1377-85.

91. Fréour T, Mirallié S, Hubert B, Splingart C, Barrière P, Maquart M, et al. Sexual transmission of Zika virus in an entirely asymptomatic couple returning from a Zika epidemic area, France, April 2016. Euro Surveill. 2016;21.

92. Froeschl G, Huber K, von Sonnenburg F, Nothdurft HD, Bretzel G, Hoelscher M, et al. Long-term kinetics of Zika virus RNA and antibodies in body fluids of a vasectomized traveller returning from Martinique: a case report. BMC Infect Dis. 2017;17:55.

93. Joguet G, Mansuy JM, Matusali G, Hamdi S, Walschaerts M, Pavili L, et al. Effect of acute Zika virus infection on sperm and virus clearance in body fluids: a prospective observational study. Lancet Infect Dis. 2017;17:1200-8.

94. Uraki R, Hwang J, Jurado KA, Householder S, Yockey LJ, Hastings AK, et al. Zika virus causes testicular atrophy. Sci Adv. 2017;3:e1602899. 
95. Matusali G, Houzet L, Satie AP, Mahé D, Aubry F, Couderc T, et al. Zika virus infects human testicular tissue and germ cells. J Clin Invest. 2018;128:4697-710.

96. Romero HA, Vargas Pavía TA, Velázquez Cervantes MA, Pliego AF, Helguera Repetto AC, Juárez ML. The dual role of the immune response in reproductive organs during Zika virus infection. Front Immunol. 2019;10:1617.

97. Bagasra O, Addanki KC, Goodwin GR, Hughes BW, Pandey P, McLean E. Cellular targets and receptor of sexual transmission of Zika virus. Appl Immunohistochem Mol Morphol. 2017;25:679-86.

98. Patel DP, Punjani N, Guo J, Alukal JP, Li PS, Hotaling JM. The impact of SARS-CoV-2 and COVID-19 on male reproduction and men's health. Fertil Steril. 2021;115:813-23.

99. Li D, Jin M, Bao P, Zhao W, Zhang S. Clinical characteristics and results of semen tests among men with coronavirus disease 2019. JAMA Netw Open. 2020;3:e208292.

100. Pan F, Xiao X, Guo J, Song Y, Li H, Patel D, et al. No evidence of SARS-CoV-2 in semen of males recovering from COVID-19. Fertil Steril. 2020;113:1135-9.

101. Wang Z, Xu X. scRNA-seq profiling of human testes reveals the presence of the ACE2 receptor, a target for SARS-CoV-2 infection in spermatogonia, Leydig and Sertoli cells. Cells. 2020;9:920.

102. Ma X, Guan C, Chen R, Wang Y, Feng S, Wang R, et al. Pathological and molecular examinations of postmortem testis biopsies reveal SARS-CoV-2 infection in the testis and spermatogenesis damage in COVID-19 patients. Cell Mol Immunol. 2021;18:487-9.

103. Yang M, Chen S, Huang B, Zhong JM, Su H, Chen YJ, et al. Pathological findings in the testes of COVID-19 patients: clinical implications. Eur Urol Focus. 2020;6:1124-9.

104. Flaifel A, Guzzetta M, Occidental M, Najari BB, Melamed J, Thomas KM, et al. Testicular changes associated with severe acute respiratory syndrome coronavirus 2 (SARS-CoV-2). Arch Pathol Lab Med. 2021;145:8-9.

105. Strebel RT, Schmidt C, Beatrice J, Sulser T. Chronic scrotal pain syndrome (CSPS): the widespread use of antibiotics is not justified. Andrology. 2013;1:155-9. 